\title{
The British Armed Services and the Participation of Minority Ethnic Communities: From Equal
} Opportunities to Diversity?

\author{
Christopher Dandeker and David Mason
}

Biographical notes:

Christopher Dandeker is Professor of Military Sociology and Head of the Department of War Studies at King's College London. He has published extensively in the field of military sociology and, most recently, on military culture, and the changing structure and missions of contemporary armed forces.

David Mason is Professor of Sociology, Associate Dean for Research and Head of the Graduate School in the Faculty of Human Sciences, at the University of Plymouth. He is well known for his work on labour market and diversity issues on which he has published extensively. 


\section{Abstract}

This paper examines the commitments enshrined in the Strategic

Defence Review White Paper to make the armed forces more genuinely representative of the British population, notably with respect to ethnicity. It identifies some conceptual problems associated with the way in which those commitments are presented and with the arguments usually deployed in support of their pursuit. It suggests that a fundamental reassessment is required of the concept of representativeness, which is at the heart of current policy commitments, if their planned practical outcomes are to be achieved. The paper asks whether a shift in focus from equal opportunities to diversity offers the prospect of resolving some of the dilemmas and obstacles identified. It concludes by suggesting that the concept of diversity is itself not unproblematic - particularly in a military context - and that it could offer a solution only if it were embraced hand in hand with a much more explicit acceptance of the diversity of the political community. This would mean nothing less than a reassessment of what it means to be British in the twenty first century and a more sophisticated grasp of what would be entailed in being representative of such a nation. 


\section{The British Armed Services and the Participation of Minority Ethnic Communities: From Equal Opportunities to Diversity?}

\section{Introduction}

The racially motivated murder of Stephen Lawrence, and the subsequent inquiry into the police's handling of its investigation (Macpherson, 1999), has raised widespread public concern about the capacity of state institutions to reflect and respond to the diversity of a multi-cultural Britain. Although the case has dramatised this issue, campaigners have long been arguing that such episodes are just the most publicly visible manifestation of a more deeply rooted problem (CRE, 1987; Panayi, 1993; Virdee, 1995),

At the same time there have, for a number of years, been persistent reports of victimisation and racism within the British armed forces as well as a significant under-representation of recruits drawn from minority ethnic communities. This last has, of course, provided prima facie evidence that the recruitment and selection process itself is also characterised by discriminatory practices. The Commission for Racial Equality has taken up the matter in the wake of a celebrated case involving the Household Cavalry. Once again, these events attracted considerable public attention, including expressions of concern from members of the royal family (CRE, 1996). 
It is no surprise, therefore, that the Home Secretary, particularly of a Labour government, has felt the need to respond with measures to address the recommendations of the Macpherson report on the Stephen Lawrence affair. In a similar vein, the Ministry of Defence, having initially been threatened with a non-discrimination notice by the CRE, has been working with the Commission to develop more effective equal opportunities policies. These commitments are exemplified by the policy pronouncements outlined in the government's Strategic Defence Review (SDR) in 1998 (Ministry of Defence, 1998), in which personnel issues were placed centre-stage in a way that had not featured in earlier defence reviews. Partly as a result, the armed forces have effected a significant transformation in their approach to equal opportunities issues to the point where the CRE has begun to portray them as an example of good practice (Equal Opportunities Review, 1999). ${ }^{1}$

Whether or not such high level expressions of a commitment to change can be translated into practice is, at one level, an empirical matter. The outcome will depend whether policy pronouncements are reflected in the beliefs and practices of lower, operational levels in the military hierarchy. In this respect the operation of the chain of command, and particularly the key roles of NCOs, represents a potential barrier to their realisation (Dandeker and Mason, 1999: 66-7). At another level, however, the outcome depends crucially on the clarity, consistency and realism with which the commitments themselves are expressed. If, as is suggested below, there are fundamental difficulties with those commitments, as 
currently formulated, significant reassessment may be required before they can be put to a realistic test. The remainder of this paper will examine the commitments enshrined in the SDR White Paper. Taking them at face value for the purposes of analysis, it will identify some conceptual problems associated with the way in which they are presented and with the arguments usually deployed in support of their pursuit. It will suggest that a fundamental re-assessment is required of the central concept of representativeness, which is at the heart of current policy commitments, if their planned practical outcomes are to have any chance of being achieved. We conclude by suggesting that, while the currently fashionable concept of diversity may offer a potential solution to some of the dilemmas we identify, this concept itself is not without its difficulties. Crucially we suggest that only under certain conditions can the diversity model offer a way forward and that this will require fundamental changes in the organisation and self-image of the armed services and the political community they serve. ${ }^{2}$

\section{Arguments for change: fairness and effectiveness}

There are, characteristically, two kinds of arguments that are adduced in support of equal opportunities measures. They appeal, respectively, to considerations of equity and fairness, and to self-interest. With regard to the first, a lack of equity is typically seen to raise issues of social justice and citizenship that have implications well beyond the boundaries of particular professions or occupations. In the case of the second, often characterised as the 'business case' for equal opportunities, the issue is 
placed firmly within the realm of self-interest rather than relying on considerations of altruism or equity. Business case arguments themselves span a range of rationales. These include questions of effective service delivery, concerns about the public image of the organisation in an environment characterised by competition for resources or market share, and issues surrounding recruitment and retention in competitive labour market conditions. They characteristically include arguments about the direct benefits of equal opportunities measures (such as an expanded recruitment pool) and about indirect benefits (such as changes in public perceptions, which may be expected to generate enhanced sales) (Iganski et al., 1998; Jewson et al., 1990; Jewson et al.1995).

Both of these kinds of arguments resonate with concerns that were made explicit in SDR. Supporting Essay 9 makes the following points:

6. We must be a modern and fair employer. We have pledged ourselves to continuous improvement in all our practices....

7. We are also committed to making real progress on improving our record on equal opportunities through tackling the complex web of underlying factors which have inhibited people from various backgrounds choosing to join us in the past. We must ensure that those who join us make progress according to their talents and legitimate aspirations. 
15. Improving Recruiting and Retention. The issues most frequently recorded by the SDR liaison team which would improve recruiting and retention included better terms and conditions of service, improvements in pay and allowances, better quality of training, reducing overstretch, allowing service beyond 22 years, providing opportunities to gain civilian qualifications during service, addressing concerns about family life, ensuring equality of opportunity [emphasis added] and providing better accommodation. (MOD, 1998, Supporting Essay 9, paras. 6-7 \& 15).

Thus a set of essentially moral arguments are reinforced by a 'business case' founded on the need to maintain or improve levels of recruitment and retention. As the perceived security of a military career has declined so, too, has the reliability of traditional recruitment pools based, for example, on locality or family tradition (Dandeker and Strachan, 1993). ${ }^{3}$ Indeed, attracting appropriate numbers of high quality recruits has already encouraged the armed services re-examine a range of traditional practices and assumptions driving their recruitment policies and practices (Dandeker and Paton, 1997).

To these influences must be added the effects of legal pressures. A series of rulings and directives will continue to flow, not only from the UK legislature, but also increasingly from such transnational bodies as the 
EU Commission and the European Court of Justice (ECJ) and the European Court of Human Rights (ECHR). In one highly contentious area of recruitment - the employment of homosexuals - the recent lifting of the formal exclusion of people on grounds of their sexual orientation was in response to a ruling from the ECHR. (Dandeker, 1999; Kier 1998; Barkawi et al., 1999). ${ }^{4}$

Such developments have already been instrumental in revolutionising the position of women within the UK armed services (Dandeker and Segal, 1996). Following a ruling that it was contrary to European Union law to require women to resign from the armed forces upon becoming pregnant, rapid and far-reaching changes have taken place. Thus, for example, women are now fully integrated into the Royal Navy, including service at sea on all types of warships other than submarines and women are being trained, and have qualified, to fly fast jet combat aircraft for the Royal Air Force.

According to SDR, ' $96 \%$ of posts in the Royal Air Force and $73 \%$ of the total posts in the Royal Navy and Royal Marines have been open to women for some time. On 1 April 1998, the Army increased the posts open to women from $47 \%$ to $70 \%$ ' (MOD, 1998 , Supporting essay 9 , para. 39). Moreover, 'Servicewomen currently represent around $7 \%$ of the total strength of the Armed Forces. More women are joining the Forces and fewer are leaving. In the last year $14 \%$ of all new recruits were women and there was a $30 \%$ decrease in the numbers leaving' 
(MOD, 1998, Supporting essay 9, para. 40). A debate continues about the integration of women into the principal roles from which they remain excluded in the Army, Royal Air Force Regiment and Royal Marines; namely those requiring them to 'close with and kill the enemy' specifically infantry and armour. It is noteworthy, however, that the SDR did not rule out future changes in this area (MOD, 1998, Supporting essay 9 , paras. $39 \& 40) .^{5}$

By contrast with this picture of rapid change, progress in increasing the recruitment and retention of members of minority ethnic groups has been slower and, until recently, had a lower public profile. Over the past five years, however, there has been a series of embarrassing allegations of discrimination and harassment. Together with an investigation by the Commission for Racial Equality (CRE, 1996), these events have combined with recruitment pressures to produce a greater recognition, on the part of the armed services, that the under-representation of minority ethnic groups is a problem.

A high profile Army recruitment initiative and a new Equal Opportunities Directive are among the most visible manifestations of public commitments to change, which were reinforced in SDR's commitment to improving the armed services' capacity to represent the whole community (MOD, 1998, Supporting Essay 9, paras. 41 \& 42). 


\section{Fairness, citizenship and the concept of representation}

Against this background, the SDR (MOD 1998) asserted the need for the armed services to reflect society. Particular emphasis was placed on the apparent under-representation of Britain's citizens of minority ethnic descent when compared with their presence in the population as a whole.

Thus, as of January 2000 , the figures for minority ethnic groups as a percentage of known strength are: for the armed services overall, $1.41 \%$, for the Naval Service, $0.91 \%$, for the Army, $1.75 \%$, and the Royal Air Force $-1.13 \%$; as a percentage of total strength, Civilian $-1.46 \%{ }^{6}$ Within this already low level, South Asian minority ethnic groups (a significant proportion of the UK minority ethnic population) are particularly underrepresented among uniformed personnel (DASA Tri-Service, 2000).

It has long been argued that the absence of proportional representation of any group within a given occupation at the very least alerts us to the possibility that arrangements for recruitment and selection are less than fully open and fair. Some would argue that under-representation itself constitutes prima facie evidence of discrimination while yet others would go further and see the absence of proportionality as itself constitutive of 'institutional racism' (cf. Jewson and Mason, 1986) ${ }^{7}$. For this reason, almost all discussions of equal opportunities issues recommend monitoring of the workforce concerning a range of characteristics in terms of which it is believed inequitable outcomes may be found. In the UK, for legal reasons, these most usually include sex, ethnicity, disability and, in 
Northern Ireland, religion. ${ }^{8}$ In almost all cases, monitoring results that reveal a lack of proportionality are seen as the starting point for a range of investigative or redressive measures. In the UK, these characteristically include the recommendation that organisations develop equal opportunities policies in the field of employment (CRE, 1984; DfEE, 1991).

It is not difficult to see that equitable representation in a key national institution is likely to be an important goal for any government committed to delivering full substantive citizenship for all members of the population. In its discussion of equal opportunities for members of minority ethnic groups, SDR set out the aim of increasing minority ethnic recruitment incrementally so that, eventually, 'the composition of our Armed Forces reflects that of the population as a whole' (MOD, 1998, Supporting Essay 9, para. 41). Although not explicitly discussed in these terms, there was a clear implication that statistically proportional representation is a worthy goal in its own right and that issues of fairness and citizenship were at stake.

In this context we should note that, although questions of citizenship have frequently figured in discussions of women's relationship to military service $^{9}$, here the issue has characteristically been phrased in terms of access to the opportunity to serve rather than in terms of proportionality of representation. This may well reflect a continuing cultural unease about the idea of women being engaged in killing - which is manifest in 
their, for now, continued exclusion from infantry and armour roles (Dandeker and Segal, 1996). In similar vein, the SDR (MOD, 1998, Supporting Essay 9, paras. $39 \& 40$ ) addresses the position of women in the following terms:

39. Women. The three Services are wholly committed to maximising opportunity for women in the Armed Forces, except where this would damage combat effectiveness. ...We have been reviewing whether we could improve the opportunities still further. As a result, we have decided that some 1300 posts in Army and Navy specialist units attached to the Royal Marines will be open to women. We have, however, concluded that posts in the Royal Marines, the RAF Regiment and those in the Army whose primary role in battle is to "close with and kill the enemy" should remain closed to women until we can properly assess, in two to three years, the impact on combat effectiveness of the recently introduced changes in the Army. Women are also currently excluded from service on submarines and as Royal Navy mine clearance divers for medical or practical reasons. Reviews of these areas will be completed towards the end of this year.

40.... We hope that the numbers of recruits will increase, particularly as the Army has specifically targeted women in its most recent recruiting campaign. Additional work is also under way to establish a system of monitoring gender related issues including 
recruiting and maternity related aspects, building on experience gained from the ethnic monitoring programme. That will provide us with objective evidence of our success, or otherwise, on gender issues.

Women's roles, then, are discussed in terms of the maximisation of opportunity. There is no suggestion that proportional representation is a goal. By contrast, minority ethnic groups are discussed in the following terms in paragraph 40 :

41. Ethnic Minorities. We are determined that the Armed Forces should better reflect the ethnic composition of the British population. Currently some $6 \%$ of the general population are from ethnic minority backgrounds, but they make up just $1 \%$ of the Services. This must not continue. We have set a goal of attracting $2 \%$ of new recruits this year from ethnic minority communities for each Service. We want that goal to increase by $1 \%$ each year so that, eventually, the composition of our Armed Forces reflects that of the population as a whole.

Here the emphasis is clearly on the proportionality of representation and the implication is clear: the absence of such statistical proportionality is itself evidence of continuing disadvantage or unfairness. This contrast in approach raises interesting questions both about the concept of 
representativeness and its relationship with notions of justice, equity and citizenship.

This equation of representation with proportionality is so commonplace in the equal opportunities literature as to amount to an orthodoxy. A closer examination, however, reveals that the concept of representation commonly has a range of alternative meanings in English. These are rarely, if ever, invoked in discussions of equal opportunities and certainly not acknowledged in the SDR. However, we believe that the distinctive features of the armed services, and their current policy dilemmas, point to the potential relevance of a more complex conceptualisation of 'representation' - one which may have a wider equal opportunities relevance. If this is so, we suggest that it important to distinguish the different meanings of representation since, as we shall see, they have potentially divergent policy implications.

We suggest it is possible to identify four distinct senses or components of representation. They are respectively: the statistical, the delegative, the symbolic and the value dimensions. By statistical representativeness, we mean an intention that the proportions of members of any group found in the armed services reflects their presence in the population as a whole. By delegative representativeness, we mean the idea that groups within the population are represented in the armed forces by some of their members but that this need not require a statistical proportionality. Thirdly, representation may have a symbolic dimension in the sense that 
the armed services may be said to be representative of something larger and more abstract, such as the country or wider political community. Finally, the armed services may be said to be representative of key values - such as honour, service, duty, and impartiality.

To claim, then, that the armed services should be representative may have, in practice, a number of implications for policy beyond measures to redress current patterns of statistical under-representation. In the following sections we consider the relevance of these different senses of representativeness for the various arguments adduced in support of equal opportunities initiatives in the armed services.

\section{Fairness as effectiveness: recruitment and retention}

We saw above that the commitments enshrined in the SDR drew heavily on arguments framed in terms of fairness or justice. This is so even although they were framed rather differently in the cases of gender and racial equality, with the discussion of women implicitly invoking the delegative sense of representativeness. (This term is, of course, not used. Indeed to do so would probably be to invite charges of 'tokenism'). At the same time, a clear business case for equal opportunities was articulated in terms of the requirements of recruitment and retention. Here then delivering the goal of fairness is held, by fortunate happenstance, simultaneously to address 'business' objectives. 
Indeed it is arguable that this business case represents a key component of attempts to cascade high level policy commitments within the armed services as a whole. Certainly the heart of the 'Policy for People' chapter of SDR is constituted by the two mutually reinforcing problems of 'undermanning' (sic) and 'overstretch' (MOD 1998, Supporting Essay 9, paras. 9-16). 'Undermanning' refers to a gap between actual and planned strengths, leading to personnel being required to work longer and harder, especially on operations. Unit overstretch is caused by a mismatch between available personnel numbers and commitments, leading to less time between tours of duty and thus less time for training, and family and personal time. Undermanning and unit overstretch then produce individual overstretch, often leading to early exit from the military; that is, poor retention which in turn exacerbates problems produced by difficulties in recruiting.

Against this background the business case for equal opportunities focuses on the possibility that tapping the pool of potential recruits in minority ethnic communities could help the armed services resolve their persistent recruitment and retention problems. This is because they would access a wider recruitment pool as they increasingly compete with civilian organisations for scarce labour, both in terms of quantity and quality. In this context we can point to the fact that minority ethnic groups, although comprising 5.5 per cent of the population of Great Britain $^{10}$, constitute 7.0 per cent of the $16-24$ military recruitment pool. (Another way of expressing this is to note that, while 16-24 year olds 
make up 12.9 per cent of the white population, they comprise 16.4 per cent of the minority ethnic population. Among some minority ethnic groups this figure is even higher. [Owen, 1996]) In addition, there is evidence to suggest that members of some minority ethnic populations are increasingly more likely than their white peers to remain in education after the age of 16 , thus providing the armed services with a useful potential additional pool of skilled labour (Modood, et al., 1997: 76-80)

These kinds of arguments linking the pursuit of self-interest to fairness through the pursuit of greater statistical representativeness are, as we have seen, common in the equal opportunities literature. However, further inspection suggests that some complex issues may be being elided in the orthodox assumptions these claims embody. The first is that greater statistical representativeness will itself deliver greater fairness and enhanced citizenship. The second is that this, in turn, will address the business case by resolving current recruitment and retention problems.

The first question to address is whether the goals expressed in SDR are achievable. The SDR aspires to a socio-demographic match between the military and society - one that can be attained through planned recruitment targets for minority ethnic groups. The difficulty is that the gross category - 'ethnic minority' - takes no account of the different socio-demographic profiles, levels of social mobility, educational attainment and cultural traditions of the very diverse groups that make up 
Britain's minority ethnic population. It is entirely conceivable that the overall target of increasing minority ethnic participation to a level commensurate with the proportion of the population classified as 'ethnic minority' could be reached without proportionality being achieved for some of the communities involved ${ }^{11}$. There is a danger that, expressed in the gross terms of the SDR, the commitment to 'representativeness' is a promise that cannot be delivered. Were this to be the case, the whole credibility of the Services' commitment to equal opportunities might be undermined. In this connection, we should note that there might be a differential propensity for members of different groups to select particular occupations or to aspire to particular careers. Given that we know that the 'white' population has not had a uniform propensity to select the armed forces as a career (Dandeker and Strachan, 1993), we should not be surprised if similar differentials were to be found among other groups.

Having said this, the armed forces could feel confident in defending a mismatch between their profile and that of society only if they could be certain it were not to be explained by a failure to have an effective equal opportunities programme. In order to be certain that completely proportional representation were, indeed, both unattainable and undesired by the groups concerned, the armed services would have to be confident that potential recruits were exercising genuinely unconstrained choices. There is no reason to believe that people are likely to aspire to careers that, for whatever reason, they regard as unattainable. At the same time there is plenty of evidence to suggest both that the aspirations 
of minority ethnic young people are high and that they are actively striving, with some success, to realise them (Modood et al. 1997: 34651). Widespread popular stereotypes notwithstanding, moreover, there is little evidence to support the claim that these aspirations are routinely unrealistic (Cross et al., 1990). Against this background, therefore, an effective action plan would have to ensure that: potential recruits were aware of the opportunities available; where appropriate, cultural and other needs were accommodated; selection policies and practices were fair and equitable; promotion and advancement opportunities were transparent and just; once recruited, the experiences of service personnel were such that they both wished to remain and were able to convey positive experiences to their friends, families and communities; and a system of monitoring, backed by rewards and sanctions, were in place to ensure compliance at all levels of the military hierarchy.

Given what was said above, however, it is at least possible that, even with effective equal opportunities policies and practices in place, differential career choices by members of different minority ethnic groups might make the aims expressed in the SDR unattainable. Where would that leave the moral and business cases for equal opportunities? What would be the implications for the expressed goal of the armed forces to reflect society?

We noted above that the SDR's commitments on equal opportunities were expressed differently in the case of women and members of 
minority ethnic groups and that, so far as women were concerned, the delegative sense of representativeness was implicitly invoked. Given this it is reasonable to ask whether, if proportionality of representation proved to be genuinely unattainable, representativeness in the delegative sense might provide an alternative way forward. In other words, it is possible to conceive of the armed forces becoming more representative in so far as they increasingly recruited members of a wide range of groups within society without statistical proportionality being achieved.

As we noted above, such a strategy is open to the charge of tokenism. Nevertheless, it is possible that the concept of diversity, which is increasingly prominent in civilian equal opportunities circles, could provide a mechanism for addressing this objection. Indeed, from this perspective, the goal of greater diversity might be best served if ethnic and other differentials in occupational aspirations were recognised and exploited.

\section{Proportionality or diversity?}

The concept of diversity means that people are valued precisely because of their differences (Kandola and Fullerton, 1998; Kandola et al., 1995; Thomas, 1991). It is assumed that different people bring different perspectives to bear and that, out of the clash of diverse viewpoints, the most innovative and efficient solutions will be generated. Moreover, the diversity model is committed to using fully the talents of individuals, allowing them to rise to the limit of their abilities. It is thus said 
simultaneously to address the needs of every individual while, at the same time, offering new flexibility to organisations in terms of their ability to mobilise human resources and respond to unpredictable environments. These claims resonate directly with arguments currently adduced for improving the equal opportunities performance of the armed services.

On the one hand tapping the pool of labour represented by minority ethnic communities is justified on the ground that the armed services would benefit from the diversity of skills and backgrounds that a broader based entry would produce. With the need for more intelligent and flexible service personnel likely to increase rather than decrease due to developments such as new technologies and more complex, politically sensitive missions (see Dandeker and Gow, 1999), it is held that such diversity is likely to prove an advantage in future years (see also Crawford 1995). At the same time valuing diversity will provide the opportunities to realise the SDR's commitment to developing a personnel strategy that could:

— enable individuals to realise their full potential during their service, provide equality of opportunity irrespective of race, gender or religion, and assist them to prepare for subsequent careers; (MOD 1998, Supporting Essay 9, para 17)

As we shall see, however, the concept of diversity is not without problems - particularly in the context of military organisations. 
In fact, the concept of diversity, as it is typically encountered in the UK, has two distinct connotations. On the one hand, it has a specifically individual focus. In this conceptualisation (which is the dominant one), modern organisations are said to operate most effectively when they harness the diverse talents of all the individuals who make up the team. This involves not merely drawing on a range of technical skills. It also entails valuing and harnessing the distinctive personal characteristics, and idiosyncracies, which different people may bring to the deliberations of the team.

On the other hand, the term diversity may also have a distinctly collective resonance. Thus it is often argued that women, as women, bring distinctive values, skills of interaction and ways of thinking to the team. As a result, more effective team building and innovative ways of problem solving may emerge. Similarly, it is sometimes argued that people from diverse cultural backgrounds can also contribute new and valued inputs. They do so because they bring personal characteristics, ways of thinking and modes of interaction that are collective in origin. In other words, then, what is being argued is that characteristics that were once seen as problematic because they embodied difference from the 'normal' and familiar, are now to be valued for the same reason.

These different connotations of diversity pose interesting further problems for the concept of statistical representativeness. In its individualist guise the concept of diversity supersedes old style conceptions of equality of 
opportunity in which the notion of proportional group representation is imbedded. In its collectivist guise, it appears to require a much more fine-tuned conception of difference than that expressed in SDR.

The utility of the concept of diversity, then, may lie in its potential to transcend the proportionality problematic and to legitimise a delegative sense of representativeness ${ }^{12}$. It is by no means clear, however, that diversity is a straightforward concept for military organisations in general and the UK armed forces in particular to embrace. Discipline, authority and conformity are typically seen as central to the social integration of military units and organisations. They are key aspects of the notions of comradeship and esprit de corps that are core components of military self-image and organisation. These characteristics of military organisations tend, in principle, to give rise to problems when confronted with difference of any kind - a fact that may help to explain some of the difficulties they encounter with homosexuality. As a result, we may legitimately ask whether a major reconceptualisation of the character of military organisations would be required for them to accommodate currently fashionable notions of diversity, a concept that necessarily implies embracing difference.

In this connection, we suggest that there are some distinctive features of British history and culture, with particular resonances within military culture, which make embracing ethnic differences particularly problematic. The contrast between the increasing participation of women 
in wider military roles and the continued difficulties experienced by Britain's citizens of minority ethnic descent may be instructive in this regard. We suggest that most of the changes in the status of women within the UK armed forces thus far contemplated have been framed within a discourse that continues to see difference as a problem. This has entailed accommodation of women to the extent that they can be made like - or represented as being like - men. Indeed, as we indicated earlier, women continue to be excluded from those roles where their physiological or presumed psychological differences from men are believed to be significant, or where the perception of such difference is held likely to undermine operational effectiveness.

By contrast, Britain's minority ethnic citizens continue to be routinely represented as different from their white peers - whether for reasons of biology, culture or history. Indeed, the relationship between citizenship and nationality poses particular problems because of the way in which both 'Englishness' and 'Britishness' have been represented as uniquely long-standing and primordial attachments (Colley, 1992; Rich, 1994). The significance of this appeal to historical continuity is greatly heightened when we consider the fact that all armed forces tend to place a very high value on tradition and history. In the case of the British armed forces, this emphasis on history has a particular significance since much of the military history of the Britain over the last two centuries or so is the history of colonial involvement. Many of the campaigns fought by the British armed forces were either against colonised peoples or to protect 
imperial territory from other colonial powers. Thus the recent forebears of many of Britain's citizens who are not white were either enemies or colonial subjects. In these circumstances, it may be difficult to view their descendants as co-nationals - whatever their formal citizenship because they lack both the common origins and the ethnic homogeneity which the British national myth, with its claims to a uniquely long history, requires.

We do not know how significant this high level cultural symbolism is for the day to day conduct of military personnel or the experiences of those of minority ethnic descent. However, nobody who has visited UK military establishments, such as the Royal Military Academy at Sandhurst, can be unimpressed by the weight of history and tradition to be found there.

Given that it is explicitly evoked in the maintenance of the esprit de corps regarded as central to operational effectiveness, it is unlikely to be without significance for future initiatives designed to ensure effective recruitment and retention of minority ethnic personnel.

\section{Conclusion}

We have argued that the apparently unproblematic concept of representativeness conceals four distinct ideas. Two of these - the statistical and, to a lesser extent, the delegative - can be seen to inform current commitments as they flow from conventional equal opportunities recommendations. We have argued that the first presents significant conceptual and practical difficulties while the second - particularly as 
manifested in the concept of diversity - is also not without problems in a military context. In other words, just as there are significant barriers to the achievement of the armed services' currently articulated goal of statistical representativeness so there are likely also to be barriers to the achievement of a strategy based on diversity. In this concluding section, we consider whether the other two senses of 'representation' - the symbolic and the value - might provide a way forward which, given their rhetoric and ideology, the armed services might be well placed to exploit.

A key problem is that the burden of history and tradition that we described above creates a situation in which the armed forces are seen, and to some extent see themselves, as symbolically representative of a political community superseded by the multi-cultural country Britain has become. One way of addressing this might be to seek explicitly to recover the historical contribution of the forebears of Britain's minority ethnic citizens to its military history, through a much more visible public celebration of their contribution to past military successes, for example in both World Wars. There is some evidence that this point has attracted some attention within the MOD but detailed policies on the matter have not, as yet been announced ${ }^{13}$.

However, accomplishing this task effectively would entail no less than creating a new version of military heritage more symbolically representative of a diverse political community. Such a strategy would seek directly to address the perceived problem of image which the armed 
forces believe undermines their attractiveness as a potential career route for minority ethnic citizens. If successful, it would provide one means to address the statistical and delegative components of representativeness by improving the attractiveness of the armed forces to potential minority ethnic recruits who would have a reason to join an organisation that more effectively presented itself as embodying their heritage as well. ${ }^{14}$

Another way of putting this is to suggest that the concept of diversity could offer a solution to current, and possible future, policy dilemmas only if it were embraced hand in hand with a much more explicit acceptance of the diversity of the political community. This would mean nothing less than a reassessment of what it meant to be British in the twenty first century and a more sophisticated grasp of what would be entailed in being representative of such a nation ${ }^{15}$. In a very real sense, then, the symbolic sense of representativeness might well be a key to delivering on commitments currently expressed in other terms. The implication of our argument is that the transformation required would entail more than the manipulation of image achieved through 'public relations', glossy advertising and high sounding statements of intent. Instead it would require root and branch changes at all levels in the military hierarchy.

Given the way in which deeply rooted tradition informs the selfperceptions as well as the external image of the armed forces, the question arises of how such a policy direction, and the radical changes it implies, could be made acceptable to those who would need to embrace 
it - particularly at key, lower operational levels. One route might be to exploit the notion of service that is central to the expressed functional raison d'être of public organisations ${ }^{16}$, and finds particularly strong and focussed expression in the armed services. Such a strategy would highlight the value dimension of representativeness by focusing on the armed forces as the embodiment of key social values. Military personnel at all levels frequently espouse the idea of service ${ }^{17}$. It is frequently argued that rendering any service to an increasingly diverse community is most readily achieved where those delivering the service are attuned to the variety of cultural needs characteristic of the population as a whole (cf. Gerrish et al., 1996; Iganski et al., 1998). It is then arguable that, as a result of their commitment to the concept of service, the armed services are well placed to marry a role as symbolic representatives of the political community with one as embodiments of key national values. These increasingly include a widely endorsed commitment to diversity as a principle of organisational and national life (Institute of Personnel and Development, n.d.). Indeed, it is possible that only by simultaneously embracing and transforming the symbolic and value senses of representativeness could the armed services, and British society more widely, begin effectively to deliver on the expressed goals of becoming more representative in the statistical and delegative senses. 


\section{Notes}

${ }^{1}$ These points emerged in discussions at the Equal Opportunities and the Armed Forces Conference, sponsored by the MOD held at the Royal Society of Arts, November 10, 1998, and at the BMSG seminar on Ethnic Minority Representation and the British Armed Forces. (BMSG 1999). See also BMSG (1998).

${ }^{2}$ We should make it clear that we are not arguing for, or endorsing, a particular normative position but are rather concerned to explore current Government commitments, taking them at face value for the purposes of analysis. Our argument is that they are replete with conceptual difficulties such that there are good reasons to believe they are, in principle, unattainable in the form currently expressed. The issue of fit (or lack of it) between these commitments and the norms followed by those who have effective day to day control over the armed services is, in our view, only one aspect of the problem. Our point, rather, is that if the high level, and high sounding, policy commitments are unrealistic and lack clarity there is little reason to believe that they could be effectively realised, whatever other problems were to be identified in such areas as the operation of the chain of command. Given this, we seek to consider whether a reappraisal of those commitments and their conceptual underpinnings could offer a way forward towards the realisation of currently espoused policy goals. We argue that such a reappraisal suggests that there may be alternative strategies but that these in turn depend for their success on a more fundamental reappraisal, not simply of operational matters of policy implementation, but of the armed services' whole conception of the political community and their relationship with it. We are, emphatically, not arguing that the concept of diversity represents some simple, magic solution to the problem of realising equal opportunities objectives in the armed services.

${ }^{3}$ There is a persistent regional dimension to the recruitment of soldiers to the British Army with about $1 / 3$ coming from the North East of the country. This point emerged in discussions with army recruitment officers.

${ }^{4}$ See Statement by Secretary of State for Defence, ECHR and the Armed Forces, 12 January 2000. It should be noted that changes had already occurred during the mid-1990s, since homosexuality, of itself, no longer constituted a criminal offence, leading instead to administrative discharge from the services (Dandeker and Paton, 1997; Harries-Jenkins and Dandeker, 1994; 1996).

${ }^{5}$ Positions in the artillery were opened to women in April 1998. An internal Army study on this issue should be completed in early 2001. The Royal Marines have succeeded in defending their requirement that all personnel - even chefs - should be prepared to serve as front line commandos, thus justifying their exclusion of women from such posts. This view was confirmed by 
the ECJ as justified on grounds of public security and as a measure that was proportional in the pursuit of that security. The same court dismissed the exclusion of women from all posts requiring the use of arms in the German army precisely because it was a blanket exclusion and not proportional. See European Court of Justice rulings on case of Angela Sirdar being employed by the Royal Marines, (26 October 1999) and the case of Tanja Kreil in the Bundeswehr, (11 January 2000). Whether the current exclusion of women from posts in infrantry and armour in the British army would be seen as proportional may not be tested in Court if the outcome of the internal review leads to a lifting of this exclusion which, at the time of writing, looks likely.

${ }^{6}$ It should be noted that known strength excludes those with no ethnic origin recorded. Total strength includes those with no ethnic origin recorded.

${ }^{7}$ For a discussion of the concept of institutional racism see Carmichael \& Hamilton, 1968;

Gillborn, 1990; Macpherson, 1999; Mason, 1982; Williams, 1985.

${ }^{8}$ For a discussion of ethnic monitoring see CRE, 1984; Jewson et al. 1992.

${ }^{9}$ See the discussions in: BMSG, 1991; Walby, 1992; Walby, 1994; Yuval-Davis, 1993; Enloe, 1983; Muir, 1993; Dandeker 1994

${ }^{10}$ According to the 1991 Census the figures are 5.5 per cent of the population of Great Britain and 6.2 per cent of the population of England.

${ }^{11}$ Recent research has demonstrated patterns of this kind in the nursing workforce, for example. See Iganski et al., 1998

${ }^{12}$ We should note, however, that embracing diversity in this sense, with the consequent deemphasis on proportionality, effectively abandons any case for equality of opportunity founded on notions of collective justice. This is because the identification of collective sources of inequality becomes increasingly difficult as the prima facie evidence of injustice provided by the proportionality test can no longer be readily uncovered (see the discussion in Mason, forthcoming).

${ }^{13}$ Conversations with MOD officials in 1999 and 2000.

${ }^{14}$ This point also connects with a broader discussion that has taken place in recent years on the need for the all-volunteer forces to remain in touch with wider society, particularly as the declining size of the armed forces has led to many people having little direct contact with service institutions or personnel. These developments have given rise to a concern that the public may not have a clear understanding of what exactly the contemporary role of the military is - particularly in a postCold war environment. Consequently, it is rather easier than before for non-military demands on public expenditure to push the armed services further down the order of spending priorities. It is for this reason that the armed forces are so concerned with the way they are portrayed and are 
keen to demonstrate not only what they do, but also that they represent the political community as a whole.

${ }^{15}$ This point has recently been made in a somewhat different context by The Commission on the Future of Multi-Ethnic Britain (The Parekh Report) (Parekh, 2000). As the report makes clear (see especially chapter 2), the image of Britain as a unified, homogeneous community of longstanding was itself always a construction (cf Colley, 1992) - a myth constantly under challenge by the persistence of Scots, Irish, Welsh and other regional identities.

${ }^{16} \mathrm{~A}$ good deal of the equal opportunities literature, as it relates particularly to public sector organisations, focuses on the question of equitable service delivery. See, for example, Gerrish et al. 1996; Iganski et al., 1998 and Jewson et al., 1995.

${ }^{17}$ In a military context the significance of service is greatly sharpened by the ever-present possibility that service could require the ultimate sacrifice of life itself.

\section{Acknowledgements}

An earlier version of this paper was presented to the biennial conference of the Inter-University Seminar on Armed Forces and Society, Baltimore, USA, October 1999. We are grateful to participants for their comments. We are also grateful to two anonymous referees whose comments have assisted us in sharpening our arguments. 


\section{References}

Barkawi, T., Dandeker, C., Wells-Petry, M., and Kier, E. (1999) 'Rights and fights: sexual orientation and military effectiveness' International Security, Vol. 24, 1: 181-201

British Military Studies Group (1991), Women in the Armed Forces: Britain in Comparative Perspective, London: BMSG

British Military Studies Group (1998) The Future of British Military Cultures, London: BMSG

British Military Studies Group (1999) Ethnic Minority Representation and the British Armed Forces, London: BMSG

Carmichael, S. and Hamilton, C.V. (1968), Black Power: the Politics of Liberation in America, London: Jonathan Cape;

Colley, L. (1992) Britons: Forging the Nation 1701-183, New Haven, Conn.: Yale University Press

Commission for Racial Equality (CRE) (1984) Code of Practice for the Elimination of Racial Discrimination in Employment, London: CRE Commission for Racial Equality (CRE) (1987) Racial Attacks: a survey in eight areas of Britain, London, CRE

Commission of Racial Equality (CRE) (1996) Report of a formal investigation into the Ministry of Defence (Household Cavalry), London: CRE

Crawford, S. R. (1995) 'Racial Integration in the Army - An Historical Perspective', British Army Review, 111, December: 24-28. 
Cross, M. et al. (1990) Ethnic Minorities and the Careers Service, Employment Department Research Paper No. 73, London: Employment Department

Dandeker, C. (1994) 'New times for the military: some sociological remarks on the changing role and structure of the armed forces of the advanced societies', British Sociological Review, 45, 4: 645-6

Dandeker, C. (1999) "'Don't ask, don't tell and don't pursue" - Is a pragmatic solution the way forward for the Armed Forces in today's society?' RUSI Journal, June, 87-89.

Dandeker, C. and Gow, J. (1999) 'Strategic Peacekeeping and Military Culture', Small Wars and Insurgencies, Winter.

Dandeker, C. and Paton, F. (1997) The Military and Social Change: A Personnel Strategy for the British Armed Forces, London Defence Studies, 39, Centre for Defence Studies, Brassey's

Dandeker, C. and Mason, D. (1999) 'Diversity in the UK armed forces: the debate about the representation of women and minority ethnic groups'. In J Soeters and J van der Meulen (eds.) Managing Diversity in the Armed Forces, Tilburg University Press: Tilburg

Dandeker, C. and Segal, M.W. (1996) 'Gender Integration in Armed Forces: Recent Policy Developments in the United Kingdom', Armed Forces and Society, Vol. 23, Number 1, Fall, 29-47

Dandeker, C. and Strachan, A. (1993) 'Soldier Recruitment to the British Army: A Spatial and Social Methodology for Analysis and Monitoring', Armed Forces and Society, Vol. 19, No. 2, Winter, 279-290. 
Defence Analytical Services Agency (DASA Tri-Service) Data supplied to authors October 2000.

Department for Education and Employment (1991) Equal Opportunities Ten-point Plan for Employers, London: DfEE.

Enloe, C. (1983) Does Khaki Become You? London: Pluto Press

Equal Opportunities Review (1999), 'A war on racism in the Armed Forces', EOR 84, March/April: 21-25

Gerrish, K., Husband, C. and Mackenzie, J. (1996) Nursing for a MultiEthnic Society, Buckingham: Open University Press.

Gillborn, D. (1990) 'Race', Ethnicity and Education, London: Unwin Hyman

Harries-Jenkins, G and Dandeker C. (1994) 'Sexual Orientation and Military Service: The British Case' in W. J. Scott and S. C. Stanley (eds.) Gays and Lesbians in the Military - Issues, Concerns and Contrasts, New York: Aldine De Gruyter.

Harries-Jenkins, G. and Dandeker, C. (1996) 'The British Case' in G Harries-Jenkins, Homosexuals in European Armed Forces, Final Technical Report, April 1996, United States Army, European Research Office, Contract Number N68171-95-C-9147: 169-188. Iganski, P., Mason, D., Spong, A. Humphreys, A. and Watkins, M. (1998) Recruiting Minority Ethnic Groups into Nursing, Midwifery and Health Visiting, London: English National Board for Nursing, Midwifery and Health Visiting, Researching Professional Education series, No. 7 
Institute of Personnel and Development (n.d.) Managing diversity: an IPD position paper, London: Institute of Personnel and Development Jewson, N. and Mason, D. (1986) 'The theory and practice of equal opportunities policies: liberal and radical perspectives', Sociological Review, 34(2): 307-334

Jewson, N., Mason, D., Waters, S. and Harvey, J. (1990) Ethnic Minorities and Employment Practice: a study of six organisations, Employment Department Research Paper No. 76, London: Employment Department Jewson, N., Mason, D., Lambkin, C. and Taylor, F. (1992) Ethnic Monitoring Policy and Practice: a Study of Employers' Experiences, Employment Department Research Paper No. 89. London: Employment Department.

Jewson, N., Mason, D., Drewett, A. and Rossiter, W. (1995) Formal Equal Opportunities Policies and Employment Best Practice, Department for Education and Employment, Research Series No. 69,London: DfEE.

Kandola, R. and Fullerton, J. (1998) Diversity in Action: Managing the Mosaic, London: Institute of Personnel and Development Kandola, R., Fullerton, J. and Ahmed, Y. (1995) 'Managing diversity: succeeding where equal opportunities have failed', Equal Opportunities Review, No. 59, January/February, pp. 31-6 Kier, E. (1998) 'Homosexuals in the U.S. Military: Open Integration and Combat Effectiveness', International Security, Vol. 23, Fall 1998, 5-39. 
Macpherson, W. (1999) The Stephen Lawrence Inquiry: Report of an Inquiry by Sir William Macpherson of Cluny, London: Home Office, Cm 4262-I.

Mason, D. (1982) 'After Scarman: a note on the concept of institutional racism', New Community, 10,1: 38-45

Mason, D. (forthcoming) 'Equality, opportunity and difference: the limits of the diversity paradigm', in Esther Breitenbach, Alice Brown, Fiona Mackay and Jan Webb (eds.) Gender Equality and the New Politics, Basingstoke, Macmillan

Ministry of Defence (MOD) (1998) The Strategic Defence Review, Cm. 3999, July.

Modood, T. et al. (1997) Ethnic Minorities in Britain, London: Policy Studies Institute

Moskos, C. and Butler, J. S. (1996) All That We Can Be, Black Leadership and Racial Integration the Army Way, Twentieth Century Fund Book, Basic Books.

Muir, K. (1993) Arms and the Woman, London: Coronet Books

Owen, D. (1996) 'Size, structure and growth of the ethnic minority populations', in D. Coleman and J. Salt (eds.) Ethnicity in the 1991 Census, Volume one: Demographic characteristics of the ethnic minority populations, London, HMSO, 1996

Panayi, P. (ed.) (1993) Racial Violence in Britain, 1840-1950, Leicester: Leicester University Press

Parekh, B. (2000) The Future of Multi-Ethnic Britain (The Parekh Report), London: Profile Books. 
Rich, P. (1994) Prospero's Return: Historical Essays on Race, Culture and British Society, London: Hansib Publishing.

Thomas, R. R. Jr., (1991) Beyond Race and Gender: unleashing the power of your total workforce by managing diversity, New York: AMACOM, American Management Association

Virdee, S. (1995) Racial violence and harassment, London: Policy Studies Institute

Walby, S. (1992) 'Woman and nation', International Journal of Comparative Sociology, XXXIII, 1-2,: 81-100;

Walby, S. (1994) 'Is citizenship gendered?' Sociology, 28, 2: 379-395.

Williams, J. (1985) 'Redefining institutional racism', Ethnic and Racial Studies, 8, 3: 323-348.

Yuval-Davis, N. (1993) 'Gender and nation', Ethnic and Racial Studies, $16,4: 621-632$ 